Canadian

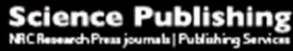

Canadian Geotechnical Journal Revue canadienne de géotechnique

\title{
SERVICEABILITY LIMIT STATE RELIABILITY-BASED DESIGN OF AUGERED CAST-IN-PLACE PILES IN GRANULAR SOILS
}

\begin{tabular}{|r|l|}
\hline Journal: & Canadian Geotechnical Journal \\
\hline Manuscript ID & cgj-2016-0146.R1 \\
\hline Manuscript Type: & Article \\
\hline Date Submitted by the Author: & 29-Aug-2016 \\
\hline Complete List of Authors: & $\begin{array}{l}\text { Reddy, Seth; GRI, Inc. } \\
\text { Stuedlein, Armin; Oregon State University, School of Civil and Construction } \\
\text { Engineering }\end{array}$ \\
\hline Keyword: & ACIP piles; Reliability; Serviceability limit state; Statistics; Design \\
\hline \multicolumn{2}{|l}{} \\
\hline
\end{tabular}

SCHOLARONE ${ }^{m}$

Manuscripts 


\title{
SERVICEABILITY LIMIT STATE RELIABILITY-BASED DESIGN OF AUGERED CAST-IN-PLACE PILES IN GRANULAR SOILS
}

\author{
Seth C. Reddy ${ }^{1}$, PhD, E.I., and Armin W. Stuedlein ${ }^{2}$, Ph.D., P.E.
}

${ }^{1}$ Staff Engineer, Geotechnical Resources, Inc. (GRI), 9750 SW Nimbus Avenue, Beaverton, OR, 97008, sreddy@gri.com

2 Associate Professor, School of Civil and Construction Engineering, Oregon State University, 101 Kearney Hall, Corvallis, OR, 97331. (541) 737-3111 armin.stuedlein@oregonstate.edu (Corresponding Author)

Page 1 of 32 


\section{ABSTRACT}

This study proposes a reliability-based design (RBD) procedure to evaluate the allowable load for augered cast-in-place (ACIP) piles installed in predominately granular soils based on a prescribed level of reliability at the serviceability limit state (SLS). The ultimate limit state (ULS) ACIP pile-specific design model proposed in the companion paper is incorporated into a bivariate hyperbolic load-displacement model capable of describing the variability in the loaddisplacement relationship for a wide range of pile displacements. Following the approach outlined in the companion paper, distributions with truncated lower-bound capacities were incorporated into the reliability analyses. A lumped load- and resistance factor is calibrated using a suitable performance function and Monte Carlo simulations. The average and conservative 95 percent lower-bound prediction intervals for the calibrated load- and resistance factor resulting from the simulations are provided. Although unaccounted for in past studies, the slenderness ratio was shown to have significant influence on foundation reliability. Because of the low uncertainty in the proposed ULS pile capacity prediction model, the use of a truncated distribution had moderate influence on foundation reliability.

Author Keywords: ACIP piles; Reliability; Serviceability limit state; Statistics; Design 


\section{INTRODUCTION}

A suitable foundation design will satisfy the strength limit or ultimate limit state (ULS) as well as the serviceability limit state (SLS), which is often associated with the allowable displacement or angular distortion of a structure. At present, the ULS has received considerably more attention in reliability-based design (RBD); however, the SLS is often the governing criterion for many foundation alternatives (Becker 1996; Wang and Kulhawy 2008; Zhang et al. 2008; Uzielli and Mayne 2011). Phoon and Kulhawy (2008) incorporated the accuracy and uncertainty of the Meyerhof (1976) method for estimating shaft resistance of drilled shafts to make assessments of reliability at the SLS for augered cast-in-place (ACIP) piles. However, the Meyerhof method was originally developed to predict the capacity of driven displacement piles and then modified for use with drilled shafts, which are constructed differently than ACIP piles. Additionally, Phoon and Kulhawy (2008) neglected toe bearing resistance when estimating ACIP pile capacity, resulting in a biased and considerably variable model (Phoon et al. 2006). Phoon et al. (2006) noted that models specific to ACIP piles needed to be developed (Phoon et al. 2006).

The goal of this study is to use the ACIP pile-specific ULS design models presented in the companion paper (Reddy and Stuedlein 2016) to investigate reliability-based SLS design of ACIP piles installed in predominately granular soils. Those case histories described in the companion paper characterized with high quality load-displacement $(Q-\delta)$ curves were used to investigate foundation reliability at the SLS. First, an approach to link the ULS capacity models developed in the companion paper to SLS design is presented. The strategy for calibrating the selected reliability-based SLS design methodology, specifically a bivariate hyperbolic loaddisplacement model, is discussed, including an effort made to treat previously un-identified dependencies of the bivariate model parameters with pile geometry. The correlation structure of the resulting transformed load-displacement model parameters is then characterized using copula 
theory, an appropriate method for simulating non-linearly correlated variables. Following Najjar and Gilbert (2009) and the approach described in the companion paper, the distribution of pile capacity is truncated as a function of the slenderness ratio to improve the estimate of reliability. Using a lumped load- and resistance factor, Monte Carlo simulations are used to estimate the uncertainty associated with the ULS and load-displacement models considering the variation in applied load and allowable displacement to estimate the reliability of ACIP piles at the SLS. Finally, a convenient set of quasi-deterministic expressions are developed to estimate the allowable load of ACIP piles installed in granular soils with a specified allowable displacement, pile geometry, and prescribed probability of exceeding the SLS. Because the simulation-based expressions necessarily include small error, a lower-bound 95 percent prediction interval for the estimation of the allowable load is also provided. This paper concludes with an illustrative example and makes comparisons to the outcome of simulations that incorporate less advantageous modeling decisions.

\section{PILE LOAD TEST DATABASE AND ULS CAPACITY MODELS}

The database used herein to evaluate the reliability of ACIP piles at the SLS consisted of the results of 95 static loading tests performed on ACIP piles constructed in principally granular soils. Owing to a relatively small contribution of shaft resistance to the total pile resistance (i.e., sum of shaft and toe bearing resistance), Kulhawy and Chen (2005) observed that the loaddisplacement behavior of shorter piles (i.e., slenderness ratio, $D / B<20$, where $B$ and $D$ are the pile diameter and embedment depth, respectively) was different than longer piles. Because very short ACIP piles are rarely constructed, the piles in this database were limited to $D / B \geq 20$; the maximum $D / B$ was equal to 68.5 . The details of the piles in the load test database are provided in the companion paper (Reddy and Stuedlein 2016). 
The models for predicting ultimate shaft and toe bearing resistance discussed in the companion paper represent the average pile response to loading after accounting for variability in pile diameter, soil and pile materials, and differences in regional construction practices and quality. The shaft and toe bearing resistances predicted using the models proposed in the companion paper were summed to produce the total predicted resistance, $Q_{u l t, p}$, and are used as a reference capacity for the SLS reliability analyses conducted herein. The mean bias, defined as the ratio of interpreted to predicted capacity, and coefficient of variation (COV), defined as the ratio of the standard deviation of the point biases to the mean bias, were equal to 0.976 and 22.4 percent, respectively, indicating predicted total resistances that are relatively unbiased and moderately variable.

\section{SERVICEABILITY LIMIT STATE DESIGN}

An appropriate approach for reliability-based calibration for SLS design includes recognition and incorporation of the sources of uncertainty that contribute to the overall reliability of the foundation system, such as the soil and pile material, construction method and quality, error associated with selected failure criteria and design model, and variation in applied loads to estimate the probability of failure, $p_{f}$, associated with exceeding a specific limit state. The $p_{f}$ is then compared to an "acceptable" level of hazard to ensure the target reliability of the system is met (Phoon and Kulhawy 2008).

The SLS is reached when foundation displacement, $\delta_{a}$, is equal to or greater than a prescribed allowable displacement, $\mu_{\delta_{a}}$. In terms of load, the SLS is defined as the case when the applied load, $Q_{a p p}$, is equal to or greater than the allowable resistance, $Q_{a}$. Ideally each $Q_{a}$ would be associated with an invariant allowable displacement and vice versa; however, significant uncertainty between these performance measures exists and therefore its characterization is 
critical for appropriate RBD. A performance function, $P$, is used to assess the probability of exceeding the SLS (Phoon and Kulhawy 2008; Uzielli and Mayne 2011; Stuedlein and Reddy 2013):

$$
p_{f}=\operatorname{Pr}\left(Q_{a}-Q_{a p p}<0\right)=\operatorname{Pr}(P<0) \leq p_{T}
$$

where $p_{T}$ is the target probability of failure. Displacement and load are related to one another through a suitable $Q-\delta$ model, selected to best represent the observed load-displacement curves in the database.

Reliability analyses at the SLS could be performed for discrete magnitudes of displacement in a manner similar to that pursued for the ULS models described in the companion paper. However, this approach is not efficient when considering several different levels of allowable displacement, which is usually prescribed based on the type, size, and criticality of the structure being considered (Phoon and Kulhawy 2008). Additionally, the allowable displacement could include considerable uncertainty given the difficulty associated with its assessment (Zhang and $\mathrm{Ng}$ 2005). Thus, an efficient RBD procedure will consider the uncertainty in the entire loaddisplacement relationship, and permit allowable displacement to be defined as a random variable.

Several sources of uncertainty influence the $Q-\delta$ behavior of ACIP piles. The use of a pile database to develop a $Q-\delta$ model permits the aleatory and epistemic uncertainty to be implicitly captured, statistically characterized, and incorporated into reliability analyses. This study followed the general framework outlined by Stuedlein and Uzielli (2014), Huffman and Stuedlein (2014), and Huffman et al. (2015) for calibration of reliability-based SLS models. The mobilized resistance, $Q_{m o b}$, at a given displacement is normalized by a reference capacity determined using the slope-tangent method (Hirany and Kulhawy 1988), $Q_{S T C}$, to reduce the observed scatter associated with various $Q-\delta$ curves. The remaining variability can be readily 
characterized using a probabilistic hyperbolic model (Phoon et al. 2006; Stuedlein and Reddy 2013):

$$
\frac{Q_{m o b}}{Q_{S T C}}=\frac{\delta_{a}}{k_{1}+k_{2} \cdot \delta_{a}}
$$

where $k_{1}$ and $k_{2}$ are physically meaningful fitting parameters that define the shape of the loaddisplacement curve: the reciprocal of $k_{1}$ and $k_{2}$ are equal to the initial slope and asymptotic (ultimate) resistance. The fitting parameters from pile case histories collected by Chen (1998) and Kulhawy and Chen (2005) were obtained directly. The observed load-displacement curves reported by O’Neill et al. (1999), Mandolini et al. (2002), McCarthy (2008), Park et al. (2010), Stuedlein et al. (2012), and DFI (2013), described in the companion paper, were fit to the hyperbolic model using ordinary least squares regression to determine $k_{l}$ and $k_{2}$ for the remaining pile cases.

The performance function may be rewritten as the difference between the mobilized resistance and applied load, and probability of failure computed as:

$$
p_{f}=\operatorname{Pr}\left(Q_{m o b}-Q_{a p p}<0\right)=\operatorname{Pr}\left(\frac{\delta_{a}}{k_{1}+k_{2} \cdot \delta_{a}}<\frac{Q_{a p p}}{Q_{S T C}}\right) \leq p_{T}
$$

The applied load and slope-tangent capacity may be expressed as the products of deterministic nominal values, $Q_{a p p, n}$ and $Q_{S T C, n}$, and their associated normalized random variables, $Q^{\prime}{ }_{a p p}$ and $m_{S T C}$, respectively (Stuedlein and Uzielli 2014, Huffman and Stuedlein 2014). As discussed subsequently, $m_{S T C}$ is defined as the ratio between the $Q_{S T C}$ and the predicted ULS capacity and is used to provide a direct method to move between the proposed ULS and SLS design methods. The ratio of $Q_{S T C, n}$ to $Q_{a p p, n}$ represents a lumped load- and resistance factor, $\psi_{Q}$, equivalent to a single deterministic global safety factor, and ensures that $p_{f}$ is equal to $p_{T}$ (Phoon 2006; Phoon 
and Kulhawy 2008; Uzielli and Mayne 2011; Stuedlein and Reddy 2013; Stuedlein and Uzielli 2014). The probability of failure is then calculated as:

$$
p_{f}=\operatorname{Pr}\left(Q_{m o b}-Q_{a p p}<0\right)=\operatorname{Pr}\left(\frac{\delta_{a}}{k_{1}+k_{2} \cdot \delta_{a}}<\frac{1}{\psi_{Q}} \frac{Q_{a p p}^{\prime}}{m_{S T C}}\right) \leq p_{T}
$$

Assuming that the performance function is normally distributed, $p_{f}$ can be mapped to the reliability index, $\beta$, defined as the number of standard deviations between the mobilized resistance and applied load, using the inverse standard normal cumulative function, $\Phi^{-1}$ :

$$
\beta=-\Phi^{-1}\left(p_{f}\right)
$$

The reliability index was estimated for a range of $\psi_{Q}$ in order to assess possible relationships between the probabilistic variables in the performance function and provide simple expressions to determine $\psi_{Q}$ given a target probability of failure.

\section{MONTE CARLO SIMULATIONS FOR RELIABILITY ANALYSES}

Although a variety of methods can be used to assess reliability at the SLS (e.g. First-Order Second Moment [FOSM], First-Order Reliability Method [FORM]), Monte Carlo simulations (MCS) were used herein because these simulations are not restricted to certain types of distributions (e.g. normal, lognormal), and are generally considered more appropriate for nonlinear limit state functions (Allen et al. 2005; Uzielli and Mayne 2011). Two main sources of uncertainty are addressed in this approach: the parameter uncertainty associated with each random variable in the performance function, and the transformation uncertainty resulting from the imperfect fit between the observed load-displacement curves and the hyperbolic model. Monte Carlo simulations were used to combine the various sources of uncertainty in order to evaluate the performance function and the associated probability of failure under several different scenarios. After determining the most appropriate distribution for each random variable in the performance function, samples were generated for each random variable based on known 
or assumed statistical parameters, and substituted into Eqn. (4) to determine $p_{f}$. Potential correlations between variables were assessed, and correlated multivariate distributions were generated using copula theory (e.g., Nelson 2006). In order to make unbiased reliability-based calibrations, correlations between variables in the performance function and deterministic variables in the database were treated via simple transformations, as described subsequently.

\section{Hyperbolic Model Parameters}

In order to make accurate assessments of reliability at the SLS for any level of allowable displacement, the uncertainty in the entire $Q-\delta$ relationship must be characterized and incorporated into the performance function. Because of their respective definitions, $k_{1}$ and $k_{2}$ are expected to be negatively correlated to some degree (Phoon et al. 2006; Stuedlein and Reddy 2013; Stuedlein and Uzielli 2014). Figure 1a shows each pair of $k_{1}$ and $k_{2}$ for the database considered, and illustrates their nonlinear correlation. Owing to its non-parametric formulation, the Kendall's Tau correlation coefficient, $\rho_{\tau}$, was used to assess the degree and direction of correlation between $k_{1}$ and $k_{2}$ and was found to equal -0.72 with a $p$-value equal to $2 \times 10^{-16}$.

To avoid bias in reliability-based assessments, the correlation between $k_{1}$ and $k_{2}$ and the available soil or geometrical parameters in the database (e.g. SPT- $N$ and $D / B$ ) must be removed or addressed in some way (Phoon and Kulhawy 2008). Using the Kendall's Tau correlation test and the database considered herein, $k_{1}$ and $k_{2}$ were found to be independent of SPT- $N$ (and therefore relative density), with $p$-values equal to 0.54 and 0.92 , respectively. However, $k_{1}$ and $k_{2}$ were found to depend on $D / B$, with $p$-values equal to $7 \times 10^{-9}$ and $6 \times 10^{-8}$, respectively. Stuedlein and Reddy (2013) showed that the correlation between the model parameters and $D / B$ can be eliminated by transforming $k_{1}$ and $k_{2}$ using:

$$
k_{1, t}=k_{1} \cdot \frac{B}{D}
$$

\section{Page 9 of 32}




$$
k_{2, t}=k_{2} \sqrt{\frac{D}{B}}
$$

The methods used to transform $k_{1}$ and $k_{2}$ into $k_{1, t}$ and $k_{2, t}$ are purely empirical, and selected on the basis that the correlation between the model parameters and slenderness ratio was eliminated. The Kendall's Tau test between $k_{1, t}$ and average SPT- $N$ along the pile shaft, $N_{a v g}, k_{2, t}$ and $N_{a v g}, k_{1, t}$ and $D / B$, and $k_{2, t}$ and $D / B$ indicated no correlation at a 5 percent level of significant, with $p$ values were equal to $0.27,0.90,0.72$, and 0.47 , respectively. Figure $1 \mathrm{~b}$ shows the pairs of $k_{l, t}$ and $k_{2, t}$ for each pile considered, which indicates that the correlation between them is largely preserved after transformation efforts are made $\left(\rho_{\tau}=-0.67, p\right.$-value $\left.=2 \times 10^{-16}\right)$.

For the purposes of simulation, several continuous probability distributions were fit to the marginal empirical distributions of $k_{1, t}$ and $k_{2, t}$ and their goodness-of-fit was assessed using the Anderson-Darling test (Anderson and Darling 1952). Convincing evidence (i.e. $p$-value $<0.05$ ) suggested that the normal, Cauchy, logistic, Weibull, and exponential distributions were not appropriate to describe the distribution of $k_{1, t}$, whereas only the Weibull and exponential distributions were rejected for fitting $k_{2, t}$ at the same level of significance. The AndersonDarling test provided no evidence (i.e. $p$-value $>0.05$ ) to reject the gamma and lognormal distributions for $k_{1, t}$, and the normal, Cauchy, logistic, gamma, and lognormal distributions for $k_{2, t}$. The gamma distribution was selected herein because it is confined to positive real values and appeared to provide the best fit to the marginal distributions of $k_{1, t}$ and $k_{2, t}$, with $p$-values equal to 0.56 and 0.68 , respectively. The probability density function for gamma-distributed random variables, $k$, is:

$$
f(k)=\frac{r^{\sigma}}{\Gamma(\sigma)} k_{i, t}^{\sigma-1} e^{-r k_{i, t}}
$$


where $\Gamma(\sigma)$ is the gamma function, and $\sigma$ and $r$ are fitting parameters. The best-fit parameters were obtained by maximum likelihood estimation, where $\sigma=4.77$ and $r=29.64$ for $k_{1, t}$, and $\sigma=$ 19.56 and $r=5.79$ for $k_{2, t}$. The empirical and fitted gamma cumulative distribution functions for $k_{1, t}$ and $k_{2, t}$ are shown in Figure $2 \mathrm{a}$ and $\mathrm{b}$, respectively.

In order to make unbiased reliability calculations, the dependence between $k_{1, t}$ and $k_{2, t}$ must be incorporated into reliability simulations (Phoon et al. 2006). Previously, correlated multivariate samples have been generated for the hyperbolic model parameters for ACIP piles using translational and rank correlation models (Phoon and Kulhawy 2008; Stuedlein and Reddy 2013); however, Li et al. (2011) showed that these methods are not appropriate for non-linear correlations. In an effort to improve the accuracy of the reliability assessments, copula theory (Nelson 2006), which separates the dependence structure of any number of correlated variables from their marginal distributions, was used to model the bivariate correlation between $k_{1, t}$ and $k_{2, t}$.

Copulas are used to simulate the multi-variate correlation structure of random variables. Five different types of copulas were evaluated for suitability in this study (Table 1; Appendix A): Gaussian, Frank (Frank 1979), Clayton (Clayton 1978), Gumbel (Gumbel 1960), and Joe (Joe 1997). Appendix A provides the functional form of each copula function, $C$, which is determined by fitting $\rho_{\tau}$ to an alternate definition of the Kendall's Tau coefficient (Nelson 2006):

$$
\rho_{\tau}\left(u_{1, t}, u_{2, t}\right)=4 \int_{0}^{1} \int_{0}^{1} C\left(u_{1, t}, u_{2, t}\right) d C\left(u_{1, t}, u_{2, t}\right)-1
$$

where $u_{1, t}$ and $u_{2, t}$ are the standardized (i.e., ranked) values of $k_{1, t}$ and $k_{2, t}$ in standard normal space. Although the Clayton, Gumbel, and Joe copulas were originally developed for use with positively correlated data, it was possible to rotate the correlation 90 degrees to model the observed negative dependence structure between $k_{1, t}$ and $k_{2, t}$, for example by replacing $u_{1, t}$ in the 
copula function by $\left(1-u_{1, t}\right)$. The copula parameters, $\theta_{i}$, (Table 1$)$ were calculated from $\rho_{\tau}$, and the best-fit copula may be determined by evaluating the Bayesian Information Criterion (BIC) (Schwarz 1978):

$$
B I C=-2 \sum_{i=1}^{N} \ln c\left(u_{1, t, i}, u_{2, t, i}\right)+k_{c} \ln N
$$

where $N$ is the sample size, $k_{c}$ is the number of copula parameters, and $c$ is the copula density function, given by:

$$
c\left(u_{1, t}, u_{2, t}\right)=\frac{\partial^{2}}{\partial u_{1, t} \partial u_{2, t}} C\left(u_{1, t}, u_{2, t}\right)
$$

Table 1 summarizes the goodness-of-fit of ranked sample data to the selected copulas. Based on the lowest BIC value, the Frank copula was the selected for reliability simulations.

To verify that the uncertainty in the observed load-displacement curves can be satisfactorily replicated using the approach described above, 1,000 $k_{1, t}-k_{2, t}$ pairs were simulated with the Frank copula and truncated gamma distributions. In order to make the comparison, $k_{1, t}$ and $k_{2, t}$ were back-transformed to $k_{1}$ and $k_{2}$ using deterministic values of $D / B$. Stuedlein and Reddy (2013) showed that different slenderness ratios are associated with different portions of the observed scatter in the $k_{1}-k_{2}$ relationship. Thus, a uniform distribution of $D / B=25,30, \ldots, 65$ was selected for reliability simulations based on the observed values in the database and their distribution.

Najjar and Gilbert (2009) illustrated the limitations associated with using random samples that follow continuous distributions to estimate reliability. Although the gamma distribution is constrained to positive values, it can lead to over-sampling at the tail ends of the distribution. Very large $k_{1}$ and $k_{2}$ pairs indicate excessive pile displacements under small applied loads and are not representative of the observed load-displacement behavior of ACIP piles. On the other hand, very small $k_{1}$ and $k_{2}$ pairs point toward an extremely stiff soil response to loading that is 
not representative of the soils represented in this database. For the purpose of simulation, the marginal distributions of $k_{1}$ and $k_{2}$ were truncated based on the observed data (Fig. 1a), such that the lower and upper bounds of $k_{1}$ and $k_{2}$ were selected equal to 0.90 and 17.0 , and 0.25 and 1.10 , respectively. Figure $3 \mathrm{a}$ and $3 \mathrm{~b}$ compare the observed and simulated model parameters, and the corresponding observed and simulated load-displacement curves. Overall, the observed scatter in the load-displacement relationship is well represented by the simulated curves and the selected range in $D / B$.

\section{Incorporation of an Ultimate Limit State Model}

One objective of this study is to link RBD of ACIP piles at the ULS with that at the SLS through the ACIP pile-specific design models developed in the companion paper (Reddy and Stuedlein 2016). Past studies on ACIP piles by Phoon et al. (2006) and Phoon and Kulhawy (2008) have sought to incorporate the accuracy and uncertainty associated with a ULS capacity prediction model into reliability assessments at the SLS using the Meyerhof method. The accuracy of the Meyerhof method was relatively good on average, with a mean bias of 1.12; however, the variability was relatively high $(\mathrm{COV}=50$ percent $)$ and biased as a function of the magnitude of nominal resistance. Owing to differences in the construction method, an ACIP pile-specific design model is preferred, and a more accurate capacity prediction model will result in a smaller load factor necessary to achieve any given target level of foundation reliability, thereby increasing the amount of useable pile capacity and the economic value of a given pile.

The mobilized resistance in the hyperbolic load-displacement model was normalized by a reference capacity determined using the slope-tangent method (Eqn. 2). Because the slopetangent method considers the shape of the load-displacement curve, piles with high asymptotic capacities are generally associated with high $Q_{S T C}$ values and vice versa; the result is a reduction in the amount of scatter in the normalized load-displacement relationship, particularly in latter 
part of the curves. However, $Q_{S T C}$ is not associated with any failure mechanisms (e.g. ultimate shaft resistance, bearing failure); instead, an estimate of pile capacity at the ULS (i.e. $\left.Q_{u l t, i}\right)$ is preferred, where familiar failure mechanisms may be represented by ULS capacity prediction models.

Since Eqn. (4) is expressed in terms of slope-tangent capacity and the $Q_{S T C}$-normalized hyperbolic model parameters, the relationship between $Q_{S T C}$ and $Q_{u l t, p}$ and the associated variability must be characterized and incorporated into the limit state equation. With this approach, the uncertainty associated with $m_{S T C}$ in Eqn. (4) is representative of the combined uncertainty from the model error associated with predicting pile capacity using the proposed ULS design models and the transformation error between $Q_{u l t, p}$ and $Q_{S T C}$. Because the proposed models in the companion paper were developed without considering $Q_{S T C}, Q_{u l t, p}$ should not be correlated with $Q_{S T C}$; however, both $Q_{S T C}$ and $Q_{u l t, p}$ should logically be correlated with the interpreted capacity, $Q_{u l t, i}$. The relationship between $Q_{u l t, p}$ and $Q_{u l t, i}$ is largely unbiased and statistically characterized with a mean bias and COV equal to 0.976 and 22.4 percent, respectively. The relationship between $Q_{S T C}$ and $Q_{u l t, i}$ was characterized using forty-two piles in the database that included enough information to calculate both definitions of capacity, resulting in a mean bias, equal to $Q_{S T C} / Q_{u l t, i}$, and COV, equal to 0.71 and 15.7 percent, respectively. The Kendall's Tau correlation coefficients between $Q_{S T C}$ and $Q_{u l t, i}$, and $Q_{u l t, i}$ and $Q_{u l t, p}$ were equal to 0.76 and 0.56 , indicating relatively strong and moderate correlations, respectively.

In order to statistically characterize the bias values relating $Q_{S T C}$ and $Q_{u l t, p}$, distributions of $Q_{u l t, i} / Q_{u l t, p}$ and $Q_{S T C} / Q_{u l t, i}$ were generated using a Monte Carlo approach and the bias statistics shown above. According to the Anderson-Darling goodness-of-fit test, the biases between $Q_{u l t, p}$ and $Q_{u l t, i}$, and $Q_{S T C}$ and $Q_{u l t, i}$ were suitably described with lognormal distributions. Based on their source distributions (i.e. lognormal) and respective statistical parameters (i.e. mean, COV), 
one million samples were generated for each distribution. The bias between $Q_{S T C}$ and $Q_{u l t, p}$ was obtained as the product of the two simulated bias distributions, where the mean bias and COV were equal to 0.69 and 27.9 percent, respectively; these values were used to statistically characterize the random variable $m_{S T C}$ in the performance function. Although $Q_{u l t, p}$ could be used in place of $Q_{S T C}$ in Eqn. (2), thereby eliminating $Q_{S T C}$ from the reliability analysis altogether, this would result in a significantly smaller reduction in the uncertainty associated with the selected $Q-\delta$ relationship (Eqn. 2). Overall, reducing the scatter in the $k_{1}-k_{2}$ relationship with $Q_{S T C}$ and accounting for the additional uncertainty from the transformation error between $Q_{u l t, p}$ and $Q_{S T C}$ produced a higher level of reliability compared to the sole use of $Q_{u l t, p}$.

\section{Assessments of Dependence Between Bivariate Model Parameters and Capacity Model Factors}

In order to provide unbiased estimates of foundation reliability, any potential dependence between the transformed hyperbolic model parameters, $k_{1, t}$ and $k_{2, t}$, and the ratio $Q_{S T C} / Q_{u l t, p}$ computed from each of the 95 case histories should also be considered and accounted for if warranted. Based on the Kendall's Tau correlation test, $\rho_{\tau}$ and the associated $p$-value between $k_{1, t}$ and $Q_{S T C} / Q_{u l t, p}$, and $k_{2, t}$ and $Q_{S T C} / Q_{u l t, p}$ were 0.30 and $2.15 \times 10^{-5}$, and -0.37 and $1.16 \times 10^{-7}$, respectively, providing strong evidence to reject the null hypotheses of independence. Copula theory (Nelson 2006) was used to describe the dependence structure between the transformed model parameters and $Q_{S T C} / Q_{u l t, p}$, and incorporated into Eqn. (4) to assess foundation reliability. Based on the AIC, the correlation between $k_{1, t}$ and $Q_{S T C} / Q_{u l t, p}$, and $k_{2, t}$ and $Q_{S T C} / Q_{u l t, p}$ is best described by a Gumbel copula rotated $180^{\circ}(\theta=1.421, A I C=-23.10)$ and a Clayton copula rotated $180^{\circ}(\theta=-0.250, A I C=-14.25)$, respectively. In order to illustrate the goodness-of-fit between the selected copulas and the observed data, 1,000 simulations were generated for each 
copula function. Figures $4 \mathrm{a}$ and $\mathrm{b}$ show the observed pairs of $k_{1, t}$ and $Q_{S T C} / Q_{u l t, p}$, and $k_{2, t}$ and $Q_{S T C} / Q_{u l t, p}$, along with the simulated data generated with the rotated Gumbel and rotated Clayton copula, respectively.

\section{Incorporation of Lower-Bound Capacities}

Horsnell and Toolan (1996), Aggarwal et al. (1996), Bea et al. (1999) and others have observed that the actual rates of failure in pile foundations are significantly less than the $p_{f}$ estimated using traditional reliability analyses. Following Najjar and Gilbert (2009), a lowerbound limit of the distribution of $m_{S T C}$ was used to improve the accuracy of the reliability simulations. The companion paper showed that a constant, $\kappa$, defined as the ratio of lower-bound to predicted resistance, could be applied to the proposed design models to estimate the lowerbound shaft and toe-bearing resistance, respectively. Using a lower-bound ratio equal to 0.35 for both shaft and toe bearing resistance, the companion paper showed that increases in foundation reliability were possible, depending on the uncertainty associated with the capacity distribution. As discussed in the companion paper, the relative contribution of shaft and toe bearing resistance varies between each pile case history; however, the lower-bound ratio associated with total resistance and applied to $m_{S T C}, \kappa$, herein can be set equal to 0.35 since the lower-bound ratio for the proposed shaft and toe bearing models is constant.

\section{Characterization of Applied Load and Allowable Displacement}

The random variables for applied load and allowable displacement in Eqn. (4) must be statistically characterized according to their mean, uncertainty, and distribution type, and these are typically dictated to the foundation designer based on structural considerations. The applied load is modeled using a lognormally distributed unit mean applied load, $Q^{\prime}{ }_{\text {app }}$ with $\mathrm{COVs}=10$ and 20 percent, corresponding to the AASHTO (2012) recommendations for dead and live load, respectively. 
The statistics used for each random variable in Eqn. (4) are shown in Table 2. Because allowable displacement depends on the size and type of the structure considered as well as the soil material properties, which influence the rate and uniformity of settlement, a range of mean allowable displacement, $\mu_{\delta_{a}}$, was considered $(2.5$ to $50 \mathrm{~mm}$ ). Previous design codes (e.g. AASHTO 1997) have specified deterministic $\delta_{a}$; however, due to the difficulties associated with predicting whether or not a structure remains serviceable at a given displacement, $\delta_{a}$ may be represented as a random variable (Zhang and $\mathrm{Ng}$ 2005). Currently, the uncertainty in $\delta_{a}$ for deep foundations is not well characterized; however, Phoon and Kulhawy (2008) and Uzielli and Mayne (2011) selected a COV equal to 60 percent based on the performance of bridges and buildings supported on shallow and deep foundations observed by Zhang and Ng (2005). To allow for flexibility in the selection of the appropriate level of uncertainty by the designer, $\delta_{a}$ was modeled using lognormal distributions with $\mathrm{COVs}=0,20,40$, and 60 percent.

\section{Reliability Simulations and Load-Resistance Factor Calibration}

Monte Carlo simulations (MCS) were used to generate 1,000,000 random samples for $\delta_{a}$, $m_{S T C}$, and $Q_{a p p}^{\prime}$ from their source distributions (Table 2$)$ to estimate the foundation reliability $(\beta$, through $\psi_{Q}$ ). The correlated transformed hyperbolic model parameters, $k_{1, t}$ and $k_{2, t}$, were sampled using copula theory and their marginal gamma distributions, and then back-transformed into $k_{1}$ and $k_{2}$ using a deterministic $D / B$ (Table 2) for use in evaluating the performance function (Eqn. 4). The final number of simulations used for computing $p_{f}$ was slightly less than 1,000,000 because the distributions associated with $m_{S T C}, k_{1}$, and $k_{2}$ were truncated. This process was repeated over $5.3 \mathrm{E}^{4}$ times in order to estimate $p_{f}$ and $\beta$ for different combinations of $\mu_{\delta_{a}}$ $(2.5,5.0, \ldots, 50 \mathrm{~mm}), \operatorname{COV}\left(\delta_{a}\right)(0,20, \ldots, 60$ percent $), \operatorname{COV}\left(Q_{\text {app }}^{\prime}\right) \quad(10,20$ percent $), \quad D / B$ $(25,30, \ldots, 65)$, and $\psi_{Q}(1.00,1.25, \ldots, 10)$. For each variable combination, Eqn. 4 is solved by 
counting the number of realizations where failure occurred (i.e. where $Q_{a p p}>Q_{m o b}$ ) relative to the total number of realizations to determine the reliability index. The MCS indicated a nonlinear trend between $\beta$ and $\psi_{Q}$ for each combination of $\mu_{\delta_{a}}, \operatorname{COV}\left(\delta_{a}\right)$, and $D / B$. Figures $5 \mathrm{a}$ and $5 \mathrm{~b}$ illustrate the outcome of the MCS in terms of the variation of $\beta$ with $\psi_{Q}$ for a $\operatorname{COV}\left(Q^{\prime}{ }_{\text {app }}{ }^{\prime}=10\right.$ percent, $\operatorname{COV}\left(\delta_{a}\right)=20$ percent and $\mu_{\delta_{a}}=2.5$ and $25 \mathrm{~mm}$, respectively. Reliability increases with $\psi_{Q}$, which acts to shift the distribution of left side of the performance function (Eqn. 4) away from the right, resulting in a decrease in the probability of failure and an increase in $\beta$. Because the conditions in Figure 5a are associated with a relatively stringent allowable displacement $\left(\mu_{\delta_{a}}\right.$ $=2.5 \mathrm{~mm})$, the $\psi_{Q}$ necessary to satisfy typical target reliability indices $(\beta=2.33$ to 3.09 , Paikowsky et al. 2004) is largely impractical $\left(\psi_{Q}>10\right)$ for most pile geometries (i.e. $\left.D / B\right)$, and reflects the well-known difficulty associated with accurately predicting small displacements of geotechnical elements. Figure $5 \mathrm{~b}$ represents the relationship between $\beta$ and $\psi_{Q}$ for a more common $\delta_{a}$. In order to limit the approach herein to practical target levels of reliability and improve the overall fit to the MCS, $\beta$ values less than zero and greater than four were discarded.

The slenderness ratio imposes a considerable effect on foundation reliability when all other variables are held constant (Stuedlein and Reddy 2013). Figure 6 shows the effect of changing $D / B$ on foundation reliability for different mean $\delta_{a}$, holding all other variables constant. At smaller allowable displacements $\left(\mu_{\delta_{a}}=10 \mathrm{~mm}\right), \beta$ is larger for a smaller $D / B$ (i.e., a stiffer pile). As allowable displacement increases, the effect of decreasing $D / B$ on $\beta$ begins to reverse, where at large allowable displacements $\left(\mu_{\delta_{a}}=50 \mathrm{~mm}\right)$ decreasing $D / B$ reduces the estimate of foundation reliability. These general trends are due to the difference in the statistical parameters of $k_{1}$ and $k_{2}$ that describe the characteristic behavior in the load-displacement relationship for different slenderness ratios. For example, a longer, less stiff pile (i.e. a larger $D / B$ ) is associated

Page 18 of 32 
with a smaller $k_{2}$ and larger $k_{1}$, which is associated with a slowly decaying load-displacement curve and less well-defined and larger asymptote. The reverse is true for shorter stiffer piles, which tend to exhibit quickly decaying load-displacement curves and a smaller more welldefined asymptote. These geometry-dependent characteristic load-displacement responses in turn affect reliability for any given set of statistical parameters in the performance function due to the way in which resistance is developed with increasing displacement and axial compression of the pile. Additionally, the selected allowable displacement (i.e. at what point on the loaddisplacement curve is considered failure) will impact reliability in a way that is dependent on load-displacement behavior and axial stiffness. This effect is most pronounced at small allowable displacements, where the load-displacement behavior of piles with differing geometries (i.e. low and high $D / B$ ) is markedly dissimilar.

For the purpose of developing convenient expressions for the calibrated $\psi_{Q}$ several different functions were evaluated for each combination of $D / B, \mu_{\delta_{a}}, \operatorname{COV}\left(\delta_{a}\right), \operatorname{COV}\left(Q_{\text {app }}{ }^{\prime}\right)$. Because of the opposing and largely nonlinear effect of increasing $\mu_{\delta_{a}}$ and $D / B$ on $\beta$, a third-order polynomial function best described the relationship between $\beta$ and $\psi_{Q}$ for each combination of the variables investigated:

$$
\psi_{Q, p}=p_{1} \beta^{3}+p_{2} \beta^{2}+p_{3} \beta+p_{4}
$$

where $\psi_{Q, p}$ is the predicted load- and resistance factor, and $p_{1}, p_{2}, p_{3}$, and $p_{4}$ are the fitting coefficients determined using least squares regression.

For each $\operatorname{COV}\left(\delta_{a}\right)$ investigated, $p_{1}, p_{2}, p_{3}$, and $p_{4}$ were found to vary logarithmically with $D / B$ and $\mu_{\delta_{a}}$. Instead of generating a complex nested function that could result in additional error, $p_{1}, p_{2}, p_{3}$, and $p_{4}$ were described using $D / B$ and $\mu_{\delta_{a}}$ simultaneously. It was observed that a 
cubic logarithmic function, which considers the interaction between $D / B$ and $\mu_{\delta_{a}}$, could be used to adequately describe the behavior of each of the fitting coefficients:

$$
\begin{aligned}
p_{1}, p_{2}, p_{3}, p_{4}=s_{1}+s_{2} \ln \left(\frac{D}{B}\right)+s_{3} \ln \left(\mu_{\delta_{a}}\right)+s_{4}\left[\ln \left(\frac{D}{B}\right)\right]^{2}+s_{5}\left[\ln \left(\mu_{\delta_{a}}\right)\right]^{2}+s_{6}\left[\ln \left(\frac{D}{B}\right)\right]^{3} \\
+s_{7}\left[\ln \left(\mu_{\delta_{a}}\right)\right]^{3}+s_{8} \ln \left(\frac{D}{B}\right) \ln \left(\mu_{\delta_{a}}\right)+s_{9}\left[\ln \left(\frac{D}{B}\right)\right]^{2} \ln \left(\mu_{\delta_{a}}\right)+s_{10} \ln \left(\frac{D}{B}\right)\left[\ln \left(\mu_{\delta_{a}}\right)\right]^{2}
\end{aligned}
$$

where $s_{1}, s_{2}, \ldots s_{10}$ are secondary fitting coefficients determined by minimizing the sum of squared error between the simulated and fitted coefficients. Table 3 shows the secondary fitting coefficients for each coefficient $\left(p_{1}-p_{4}\right)$ and $\operatorname{COV}\left(\delta_{a}\right)$, for $\operatorname{COV}\left(Q^{\prime}{ }_{a p p}\right)=10$ and 20 percent. It is noted that Eqn. (11) was developed using specific ranges for foundation reliability (i.e. $0<\beta<$ 4) and loading factors $\left(1<\psi_{Q}<10\right)$, and extrapolation beyond these bounds is not recommended. In addition, the bounds of the dependent variables in Eqn. (12) shown in Table 2 should not be exceeded.

\section{Accuracy and Uncertainty of the Closed-Form Solution}

The accuracy and uncertainty of Eqn. (11) was evaluated using 1,000 uniform random samples of $\mu_{\delta_{a}}, D / B$, and $\psi_{Q}$ from Table 2 for $\operatorname{COV}\left(Q^{\prime}{ }_{a p p}\right)=10$ and 20 percent and $\operatorname{COV}\left(\delta_{a}\right)=0$, 20, 40, and 60 percent. The reliability index was then substituted into Eqn. (11) to calculate $\psi_{Q, p}$, and compared to the value resulting from the MCS. In general, the mean bias for each $\operatorname{COV}\left(Q_{\text {app }}^{\prime}\right)$ and $\operatorname{COV}\left(\delta_{a}\right)$ combination was equal to one, and the $\operatorname{COV}$ ranged from 2.4 to 3.9 percent, indicating acceptably small error. Figure 7 presents a comparison of simulated and predicted $\psi_{Q}$ for $\operatorname{COV}\left(Q^{\prime}{ }_{\text {app }}\right)$ equal to 10 percent and $\operatorname{COV}\left(\delta_{a}\right)=0,20,40$, and 60 percent. 
Although the uncertainty associated with Eqn. (11) is relatively small, the $\psi_{Q}$ required to achieve a desired level of foundation reliability may be under-estimated. Therefore, a conservative 95 percent prediction of $\psi_{Q, p}$, termed the lower-bound load- and resistance factor, $\psi_{Q, L B}$, can be estimated by adding $\psi_{Q, p}$ with a lower-bound constant, $c_{L B}$. Table 4 shows $c_{L B}$ for each $\operatorname{COV}\left(Q^{\prime}{ }_{a p p}\right)$ and $\operatorname{COV}\left(\delta_{a}\right)$ combination. In general, relatively small increases in $\psi_{Q, p}$ are needed to satisfy the target foundation reliability at a 95 confidence level for the range of $\psi_{Q, p}$ considered. For example, for a $\operatorname{COV}\left(Q^{\prime}{ }^{\prime}{ }_{a p}\right)=10$ percent and $\operatorname{COV}\left(\delta_{a}\right)=20$ percent and $\psi_{Q, p}=3$, $\psi_{Q, p}$ must be increased by 0.20 (i.e., 7 percent) in order satisfy the specified target reliability with a 95 percent confidence level.

\section{APPLICATION OF THE RELIABILITY-BASED SLS DESIGN APPROACH}

In order to illustrate the intended use of the proposed reliability-based serviceability limit state design approach, a typical design scenario for a structure supported on widely-spaced ACIP piles installed in predominately granular soils is described. Figure 8 is presented alongside the example in order to clearly illustrate the general process to determine the load-resistance factor for a given pile geometry, allowable displacement and associated uncertainty, target probability of failure, and uncertainty associated with applied load. For this example, the nominal pile diameter, $B$, and length, $D$, were selected as $400 \mathrm{~mm}$ and $12 \mathrm{~m}$, respectively, indicating a slenderness ratio, $D / B$, equal to 30 . The nominal allowable pile displacement was assumed to be $25 \mathrm{~mm}$, with moderate uncertainty $\left(\operatorname{COV}\left(\delta_{a}\right)=20\right.$ percent). In this example, the variation in the applied load, $\operatorname{COV}\left(Q_{\text {app }}^{\prime}\right)$, was assumed equal to 10 percent. The uncertainty in $N_{1,60}$ is included in this approach by directly incorporating the uncertainty in the proposed ULS design models. The procedure for estimating the allowable load with a target probability of exceeding the SLS equal to 1 percent $(\beta=2.33)$ is outlined below:

Page 21 of 32 
1. Estimate the nominal pile capacity, $Q_{u l t, p}$, using the ULS design models proposed in the companion paper (Reddy and Stuedlein 2016), and site-specific soil characteristics (i.e. vertical effective stress, SPT- $N$ ).

2. Determine the appropriate predicted load- and resistance factor, $\psi_{Q, p}$, using Eqn. (11) and $\beta=2.33$. The coefficients $p_{1}$ through $p_{4}$ are calculated using Eqn. (12) and the aforementioned mean $\delta_{a}$ and slenderness ratio. The secondary coefficients, $s_{1}$ through $s_{10}$, are obtained from Table 3 based on the variation in applied load and $\delta_{a}$.

3. The resulting load- and resistance factor was determined equal to 2.75 , and was then adjusted to reflect the 95 percent lower-bound load-resistance factor, $\psi_{Q, L B}$, by adding $c_{L B}$ from Table 4 to $\psi_{Q}$, which corresponds to the selected variation in applied load and allowable displacement. For the desired $\beta=2.33, \psi_{Q, L B}$ equals 2.95 .

4. The allowable load that limits displacement to $25 \mathrm{~mm}$ or less with a probability of exceeding the SLS equal to 1 percent is then computed as $\left(1 / \psi_{Q, L B}\right) Q_{u l t, p}=0.34 Q_{u l t, p}$.

Instead, if a larger variation in allowable displacement had been selected $\left(\operatorname{COV}\left(\delta_{a}\right)=60\right)$, holding all other variables constant and repeating steps 1 through 4 , the allowable load would be equal to $0.32 Q_{u l t, p}$. This represents a 6 percent reduction in the amount of allowable load, compared to the allowable load when $\operatorname{COV}\left(\delta_{a}\right)=20$ percent.

The impact of pile geometry (i.e. slenderness ratio) on reliability on the load- and resistance factor is illustrated by holding $\mu_{\delta_{a}}, \operatorname{COV}\left(\delta_{a}\right), \operatorname{COV}\left(Q_{\text {app }}^{\prime}\right)$, and the target $\beta$ constant based on the design example shown above, and changing the slenderness ratio from 30 to 60 . Because the impact of $D / B$ on $\psi_{Q}$ was observed to the most significant at the low and high ends of the range of $\mu_{\delta_{a}}$ considered (i.e. 2.5 and $50 \mathrm{~mm}$ ), and the smallest changes in $\psi_{Q}$ occur at moderate $\mu_{\delta_{a}}$ (i.e. $25 \mathrm{~mm}$, Fig. $4 \mathrm{~b})$, the change in $\psi_{Q}$ was relatively small (2.75 to 2.72$)$. If instead $\mu_{\delta_{a}}=15 \mathrm{~mm}, \psi_{Q}$ 
equals 3.06 and 3.60 for $D / B=30$ and 60 , respectively, and represents a considerable reduction (15 percent) in the allowable load (i.e. $0.33 Q_{u l t, p}$ to $0.28 Q_{u l t, p}$ ). Note that a similar reduction in allowable load was observed in the example above when $\operatorname{COV}\left(\delta_{a}\right)$ was increased from 20 to 60 percent.

To understand the impact of truncated distributions on foundation reliability at the SLS, MCS were carried out with and without truncated distributions of $m_{S T C}$. Assuming that $m_{S T C}$ is truncated with the proposed lower-bound limit equal to $0.35, \mu_{\delta_{a}}=15 \mathrm{~mm}, \operatorname{COV}\left(\delta_{a}\right)=20$ percent, $\operatorname{COV}\left(Q_{\text {app }}\right)=10$ percent, $\psi_{Q}=3$, and $D / B=30, \beta$ was found to equal $2.36\left(p_{f}=0.91\right.$ percent). In comparison, $\beta$ was equal to $2.35\left(p_{f}=0.94\right.$ percent $)$ when a full continuous distribution (non-truncated) of $m_{S T C}$ was used. This example represents a change of -0.01 or a 3.2 percent decrease in the estimated probability of failure when lower-bound resistances are considered. The magnitude of change in $\beta\left(p_{f}\right)$ observed in this example is primarily attributed to the relatively small COV associated with $m_{S T C}(27.9$ percent), and is largely consistent with the findings presented in Najjar (2005) and Najjar and Gilbert (2009) who showed the effect of lower-bound resistance limits on reliability was directly related to the amount of variability in the distribution of resistance. Because the distribution of $m_{S T C}$ was truncated directly, rather than to the entire left side of Eqn. (4), the effect of a lower-bound resistance limit on $\beta$ is expected to be relatively constant for each combination of simulated variables (i.e. $\mu_{\delta_{a}}, \operatorname{COV}\left(\delta_{a}\right), \operatorname{COV}\left(Q^{\prime}{ }_{a p p}\right)$, $\left.D / B, \psi_{Q}\right)$. The use of $\beta=2.33$ in this example is to aid comparison to the ULS capacities described by Reddy and Stuedlein (2016) in the companion paper; however, reliability indices for SLS should likely be lower owing to the reduced consequences of "failure" (i.e., exceeding the target displacement) for the SLS. For example, Eurocode 7 (e.g., Orr and Breysse, 2008) includes SLS provisions of $\beta=1.5$ (or $p_{f}=6.7 \%$ ) over a 50 -year service life. 
The Eurocode design standard BS EN1990:2002 (British Standards Institute, 2002) recommends a one-year target reliability index at the SLS equal to 2.9. Using the translational correlation model and ULS statistics developed using Meyerhof (1976), Phoon and Kulhawy (2008) showed that a target $\beta=2.6$ recommended by Phoon et al. (1995) for transmission line structures necessitated a mean factor of safety of about 4 for $\mu_{\delta_{a}}=25 \mathrm{~mm}$ and $\operatorname{COV}\left(\delta_{a}\right)=60 \%$; the more stringent BS EN1990:2002 target $\beta$ was met using a mean factor of about 4.6. Using the same statistics for allowable displacement and applied load, and a slenderness ratio of $30, \psi_{Q}$ $=3.6$ and 4.2 was necessary to satisfy a $\beta=2.6$ and 2.9 , respectively.

\section{CONCLUSIONS}

In this study, a reliability-based design (RBD) methodology for estimating the allowable load at a prescribed allowable displacement and target probability of exceeding the SLS has been developed for ACIP piles installed in predominately granular soils. Consistent with Phoon and Kulhawy (2008) and Stuedlein and Reddy (2013), a hyperbolic model provided a good fit to the load-displacement curves for ACIP piles for the database considered herein, where the uncertainty in the aggregated load-displacement relationship is described using a correlated bivariate vector containing the hyperbolic model parameters. In order to account for the intercorrelation between the model parameters, several copula functions were assessed based on the goodness-of-fit to the load test database. Because of their physically-meaningful definitions, the hyperbolic model parameters were found to be strongly correlated with pile slenderness ratio, defined as the ratio of pile length to diameter. It was determined that the pile length has a strong impact on the estimate of reliability.

To date, an ACIP pile-specific ultimate limit state (ULS) model has not been included in the assessment of foundation reliability at the SLS. The ULS models proposed in the companion paper were incorporated in the analyses herein by evaluating the relationship between the 
selected reference capacity and ULS predicted capacity using a Monte Carlo approach. The combined variability resulting from the error associated with the ULS capacity prediction model and the transformation error between the reference capacity and the ULS predicted capacity was included in this approach.

Owing to the differences between the estimated probabilities of failure and actual observed instances of failure for many deep foundation elements, this study truncated the otherwise continuous distribution of pile capacity. In order to provide a more general approach to evaluating reliability at the SLS, several different combinations of mean allowable displacement, uncertainty in allowable displacement and applied load, and slenderness ratio, were used to calibrate the load-resistance factor. A convenient set of expressions was then provided to estimate the lumped load-resistance factor associated with a target level of reliability given prescribed levels of the independent design variables to facilitate a quasi-deterministic design framework. Although the uncertainty associated with estimating the load- and resistance factor was small, 95 percent prediction intervals were provided to provide an accurate and conservative load- and resistance factor. A design example was included in order to illustrate the use of the closed-form solution, and a brief parametric study is performed to illustrate the impact of slenderness ratio on the estimated load- and resistance factor, and the effect of truncated distributions on foundation reliability. The proposed procedure should not be used for design scenarios outside those included in the database, or for load- and resistance factors and target levels of reliability greater than those considered herein.

\section{ACKNOWLEDGEMENTS}

The authors wish to acknowledge the Rickert Fellowship and the School of Civil and Construction Engineering at Oregon State University for their support that made this work possible. 


\section{REFERENCES}

Aggarwal, R.K., Litton, R.W., Cornell, C.A., Tang, W.H., Chen, J.H., and Murff, J.D. 1996. Development of pile foundation bias factors using observed behavior of platforms during hurricane Andrew. In Proceedings of the Offshore Technology Conference, Houston, Texas, 6-9 May 1996. pp. 445-455.

Akaike, H. 1974. A new look at the statistical model identification. IEEE Transactions on Automatic Control, 19(6): 716-723.

Allen, T.M., Nowak, A.S., and Bathurst, R.J. 2005. Calibration to determine load and resistance factors for geotechnical and structural design. Transportation Research Board Circular EC079, Transportation Research Board, Washington, D.C.

American Association of State Highway and Transportation Officials (AASHTO). 1997. LRFD Bridge Design Specifications. American Association of State Highway and Transportation Officials, Washington, D.C.

American Association of State Highway and Transportation Officials (AASHTO). 2012. LRFD Bridge Design Specifications. 6th ed. American Association of State Highway and Transportation Officials, Washington, D.C.

Anderson, T.W., and Darling, D.A. 1952. Asymptotic theory of certain goodness-of-fit criteria based on stochastic processes. The Annals of Mathematical Statistics, 23(2): 193-212.

Bea, R.G., Jin, Z., Valle, C., and Ramos, R. 1999. Evaluation of reliability of platform pile foundations. Journal of Geotechnical and Geoenvironmental Engineering, 125(8): 696-704.

Becker, D. E. 1996. Limit states design for foundations part II: development for national building code of Canada. Canadian Geotechnical Journal, 33(6): 984-1007.

British Standards Institute. 2002. Eurocode: basis of structural design. BS EN1990:2002, London. 
Brown, D.A., Dapp, S.D., Thompson, W.R., and Lazarte, C.A. 2007. Design and construction of continuous flight auger piles. Geotechnical Engineering Circular 8, Federal Highway Administration, Washington, D.C.

Chen, J.R. 1998. Case history evaluation of axial behavior of augered cast-in-place piles and pressure-injected footings. M.S. Thesis, School of Civil and Environment Engineering, Cornell University, Ithaca, NY.

Clayton, D.G. 1978. A model for association in bivariate life tables and its application in epidemiological studies of familial tendency in chronic disease incidence. Biometrika, 65: 141-152.

Deep Foundation Institute (DFI). 2013. Personal Communication. Corvallis, OR.

Frank, M.J. 1979. On the simultaneous associativity of $\mathrm{F}(\mathrm{x}, \mathrm{y})$ and $\mathrm{x}+\mathrm{y}-\mathrm{F}(\mathrm{x}, \mathrm{y})$. Aequationes Mathematicae, 19: 194-226.

Gumbel, E.J. 1960. Bivariate exponential distributions. Journal of the American Statistical Association, 55: 698-707.

Hirany, A., and Kulhawy, F.H. 1988. Conduct and interpretation of load tests on drilled shaft foundations, volume 1: detailed guidelines. Electric Power Research Institute Report EL5915-V1, Electric Power Research Institute, Palo Alto, CA.

Horsnell, M.R., and Toolan, F.E. 1996. Risk of foundation failure of offshore jacket piles. In Proceedings of the Offshore Technology Conference, Houston, Texas, 6-9 May 1996, 381392.

Huffman, J.C. and Stuedlein, A.W. 2014. Reliability-based Serviceability Limit State Design of Spread Footings on Aggregate Pier Reinforced Clay. Journal of Geotechnical and Geoenvironmental Engineering, ASCE, 140(10): 04014055. 
Huffman, J.C., Strahler, A.W., and Stuedlein, A.W. 2015. Reliability-based Serviceability Limit State Design for Immediate Settlement of Spread Footings on Clay. Soils and Foundations, 55(4): 798-812.

Joe, H. 1997. Multivariate models and dependence concepts. Chapman \& Hall, London.

Kulhawy, F.H., and Chen, J.R. 2005. Axial compression behavior of augered cast-in-place (ACIP) piles in cohesionless soils. In Proceedings of Advances in Designing and Testing of Deep Foundations: In Memory of Michael W. O’Neill, Geotechnical Special Publication 129, Austin, Texas, 24-26 January 2005. American Society of Civil Engineers, Virginia, pp. 275289.

Li, D.Q., Tang, X.S., Phoon, K.K., Chen, Y.F., and Zhou, C.B. 2013. Bivariate simulation using copula and its application to probabilistic pile settlement analysis. International Journal for Numerical and Analytical Methods in Geomechanics, 37(6): 597-617.

Mandolini, A., Ramondini, M., Russo, G., and Viggiani, C. 2002. Full scale loading tests on instrumented CFA piles. In Deep Foundations: An International Perspective on Theory, Design, Construction, and Performance, Geotechnical Special Publication 116, Orlando, Florida, 14-16 February 2002. American Society of Civil Engineers, Virginia, pp. 10881097.

McCarthy, D.J. 2008. Empirical relationships between load test data and predicted compression capacity of augered cast-in-place piles in predominately cohesionless soils. M.S. Thesis, Department of Civil, Environmental, and Construction Engineering, The University of Central Florida, Orlando, FL.

Meyerhof, G.G. 1976. Bearing capacity and settlement of pile foundations. Journal of Geotechnical Engineering Division, 102(3): 195-228. 
Najjar, S.S. 2005. The importance of lower-bound capacities in geotechnical reliability assessments. Ph.D. Dissertation, The University of Texas at Austin, Austin, TX.

Najjar, S.S., and Gilbert, R.B. 2009. Importance of lower-bound capacities in the design of deep foundations. Journal of Geotechnical and Geoenvironmental Engineering, 135(7): 890-900.

Nelson, R.B. 2006. An Introduction to Copulas. 2nd ed. Springer, New York, NY.

O’Neill, M.W., Vipulanandan, C., Ata, A., and Tan, F. 1999. Axial performance of continuous flight auger piles for bearing. Texas Department of Transportation Report 7-3940-2, Texas Department of Transportation, Austin, Texas.

Orr, T.L., Breysse, D., 2008. Eurocode 7 and reliability-based design. Reliability-based Design in Geotechnical Engineering: Computations and Applications. Chapter 8. In: Phoon, K.K. (Ed.), Taylor and Francis, pp. 298-343

Paikowsky, S. G., with contributions from Birgisson, B., McVay, M.C., Nguyen, T., Kuo, C., Baecher, G., Ayyab, B., Stenersen, K., O’Malley, K., Chernauskas, L. and O’Neill, M.W., 2004. Load and resistance factor design (LRFD) for deep foundations. National Cooperative Highway Research Program Report 507, Transportation Research Board, National Research Council, Washington, D.C.

Park, S., Roberts, L.A., and Misra, A. 2010. Characterization of t-z parameters and their variability for auger pressure grouted piles using field load test data. In GeoFlorida: Advances in Analysis, Modeling, and Design, Geotechnical Special Publication 199, Orlando, Florida, 20-24 February 2010. American Society of Civil Engineers, Virginia, pp. 1757-1766.

Phoon, K.K., and Kulhawy, F.H. 2008. Serviceability limit state reliability-based design. In Reliability-Based Design in Geotechnical Engineering: Computations and Applications. Edited by K.K. Phoon, Taylor and Francis Group, London, 344-384.

Page 29 of 32 
Phoon, K.K., Kulhawy, F.H., and Grigoriu, M.D. 1995. Reliability-based design of foundations for transmission line structures. Report TR-105000, Electric Power Research Institute (EPRI), Palo Alto, CA.

Phoon, K.K., Chen, J.R., and Kulhawy, F.H. 2006. Characterization of model uncertainties for auger cast-in-place (ACIP) piles under axial compression. In Foundation Analysis and Design: Innovative Methods, Geotechnical Special Publication 153, Shanghai, China, 6-8 June 2006. American Society of Civil Engineers, Virginia, pp. 82-89.

Reddy, S.C., and Stuedlein, A.W. 2016. Ultimate limit state reliability-based design of augered cast-in-place piles considering lower-bound capacities. Canadian Geotechnical Journal, Companion Paper: Under Review.

Schwarz, G. 1978. Estimating the dimension of a model. The Annals of Statistics, 6(2): 461-464.

Stuedlein, A.W., and Reddy, S.C. 2013. Factors affecting the reliability of augered cast-in-place piles in granular soils at the serviceability limit state. Journal of the Deep Foundations Institute, 7(2): 46-57.

Stuedlein, A.W., and Uzielli, M. 2014. Serviceability limit state design for uplift of helical anchors in clay. Geomechanics and Geoengineering, 9(3): 173-186.

Stuedlein, A.W., Neely, W.J., and Gurtowski, T.M. 2012. Reliability-based design of augered cast-in-place piles in granular soils. Journal of Geotechnical and Geoenvironmental Engineering, 138(6): 709-717.

Uzielli, M., and Mayne, P., 2011. Serviceability limit state CPT-based design for vertically loaded shallow footings on sand. Geomechanics and Geoengineering, 6(2): 91-107.

Wang, Y., and Kulhawy, F. 2008. Reliability index for serviceability limit state of building foundations. Journal of Geotechnical and Geoenvironmental Engineering 134(11): 15871594.

Page 30 of 32 
Zhang, L.M., and Ng, A.M.Y. 2005. Probabilistic limiting tolerable displacements for serviceability limit state design of foundations. Geotechnique, 55(2): 151-161.

Zhang, L.M., Xu, Y., and Tang, W.H. (2008). Calibration of models for pile settlement analysis using 64 field load tests. Canadian Geotechnical Journal, 45(1): 59-73.

Page 31 of 32

https://mc06.manuscriptcentral.com/cgj-pubs 


\section{Figure Captions}

Fig. 1. The hyperbolic model parameters, $k_{1}$ and $k_{2}$, (a) and the transformed parameters, $k_{l, t}$ and $k_{2, t}$, (b) and their correlation.

Fig. 2. The empirical and fitted gamma marginal distributions and corresponding statistical parameters for (a) $k_{1, t}$ and (b) $k_{2, t}$.

Fig. 3. Comparison of the observed and 1,000 simulated (a) model parameters, $k_{1}$ and $k_{2}$, and (b) corresponding load-displacement curves.

Fig. 4. The goodness-of-fit between the observed and simulated data for (a) $k_{1, t}$ and $Q_{S T C} / Q_{u l t, p}$, using a Gumbel copula rotated $180^{\circ}$ and (b) $k_{2, t}$ and $Q_{S T C} / Q_{u l t, p}$ using a Clayton copula rotated $180^{\circ}$.

Fig. 5. The relationship between load-resistance factor and reliability index for $\operatorname{COV}\left(Q_{\text {app }}{ }^{\prime}=10\right.$ percent and $\operatorname{COV}\left(\delta_{a}\right)=20$ percent for (a) a mean allowable displacement of $2.5 \mathrm{~mm}$ and (b) $25 \mathrm{~mm}$ and for slenderness ratios of 25 to 65 .

Fig. 6. The effect of slenderness ratio of reliability at the serviceability limit state for different mean allowable displacements and constant values of $\operatorname{COV}\left(\delta_{a}\right), \operatorname{COV}\left(Q^{\prime}{ }_{\text {app }}\right)$, and $\psi_{Q}$.

Fig. 7. Comparison of simulated and predicted load-resistance factors using the proposed serviceability limit state model for $\operatorname{COV}\left(Q^{\prime}\right.$ app $)$ equal to 10 percent and $\operatorname{COV}\left(\delta_{a}\right)=0,20$, 40 , and 60 percent.

Fig 8. Procedure for implementation of the proposed reliability-based serviceability limit state methodology to determine the load-resistance factor for ACIP piles in predominately granular soils.

Page 32 of 32 


\section{APPENDIX A}

In order to model the correlation structure of the transformed hyperbolic model parameters, $k_{1, t}$ and $k_{2, t}$, the following five copula functions were considered (Nelson 2006), including the Gaussian copula:

$$
C_{c_{1}, c_{2}}=\Phi_{\theta}\left(\Phi^{-1}\left(u_{1, t}\right), \Phi^{-1}\left(u_{2, t}\right)\right)
$$

the Frank copula:

$$
C_{c_{1}, c_{2}}=-\frac{1}{\theta} \ln \left(1+\frac{\left(e^{-\theta \cdot u_{1, t}}-1\right)\left(e^{-\theta \cdot u_{2, t}}-1\right)}{e^{-\theta}-1}\right)
$$

the Clayton copula:

$$
C_{c_{1}, c_{2}}=\left(u_{1, t}^{-\theta}+u_{2, t}^{-\theta}-1\right)^{-\frac{1}{\theta}}
$$

the Gumbel copula:

$$
C_{c_{1}, c_{2}}=e^{-\left(\left(-\ln \left(u_{1, t}\right)\right)^{p}+\left(-\ln \left(u_{2, t}\right)\right)^{p}\right)^{\frac{1}{\theta}}}
$$

and the Joe copula:

$$
C_{c_{1}, c_{2}}=1-\left(\left(1-u_{1, t}\right)^{\theta}+\left(1-u_{2, t}\right)^{\theta}-\left(1-u_{1, t}\right)^{\theta} \cdot\left(1-u_{2, t}\right)^{\theta}\right)^{\frac{1}{\theta}}
$$

where $\theta=$ the copula parameter determined by fitting as described in the manuscript and $u_{1, t}$ and $u_{2, t}$ are the standardized (i.e., ranked) values of $k_{1, t}$ and $k_{2, t}$ in standard normal space. 

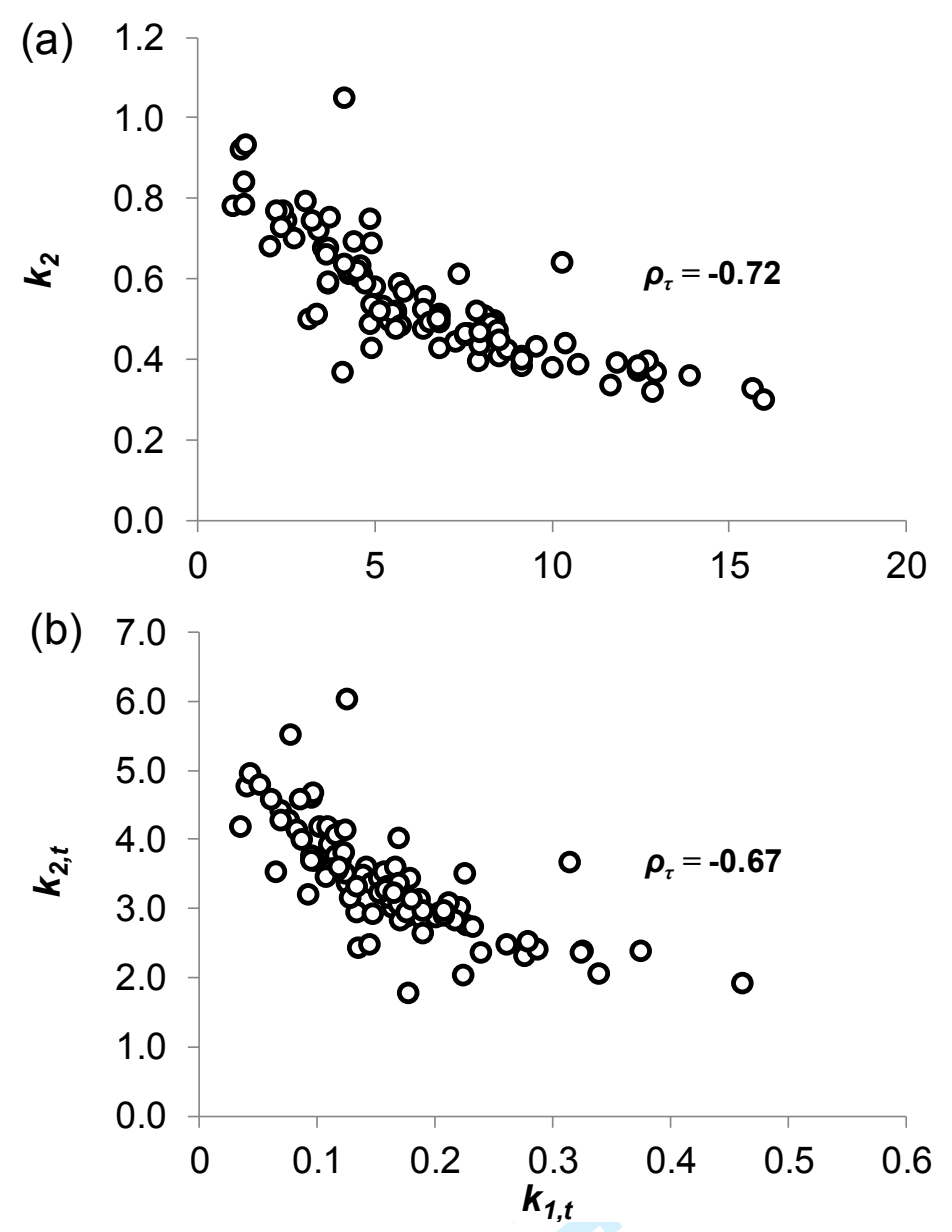

Fig. 1. The hyperbolic model parameters, $k_{1}$ and $k_{2}$, (a) and the transformed parameters, $k_{1, t}$ and $k_{2, t}$, (b) and their correlation. 

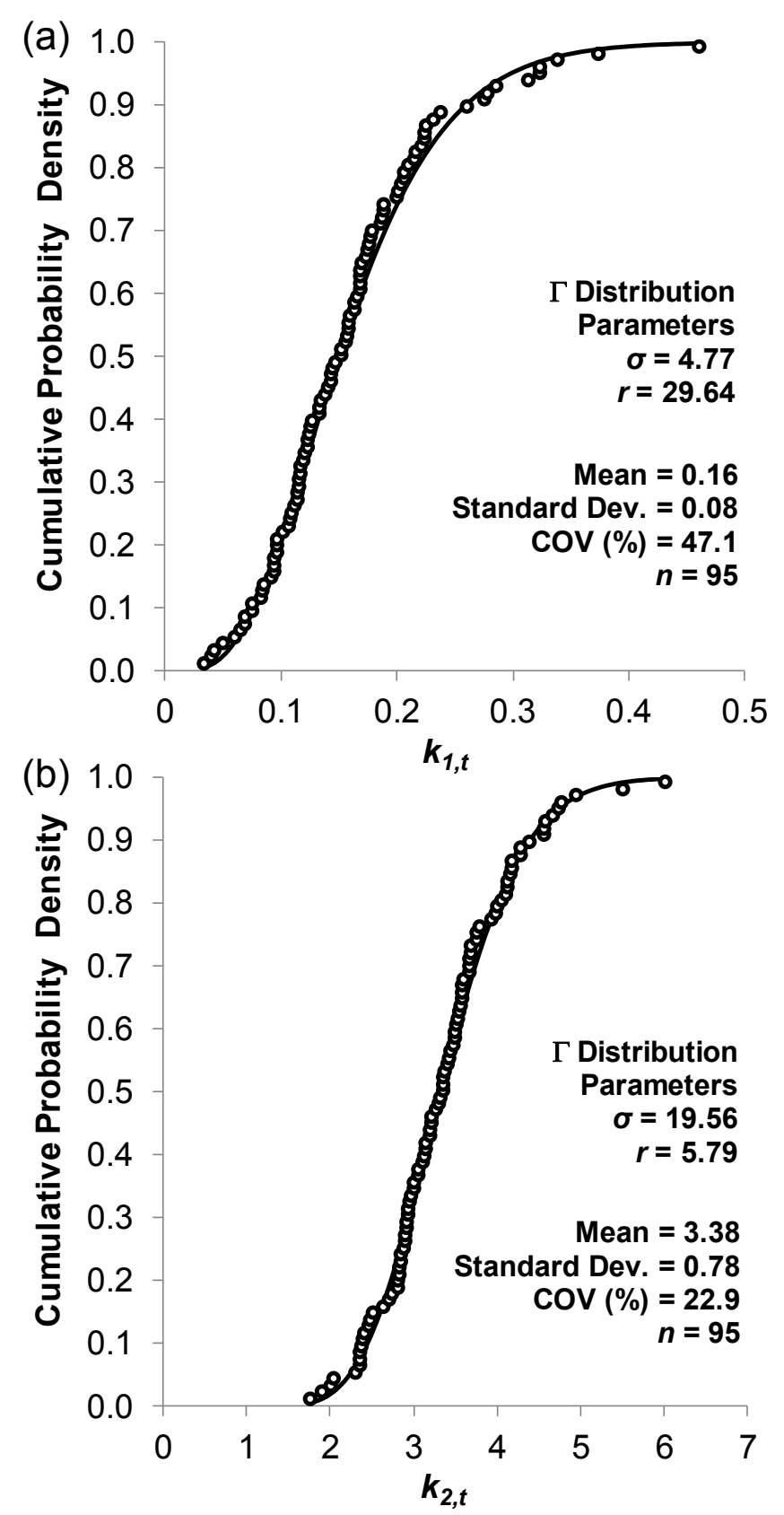

Fig. 2. The empirical and fitted gamma marginal distributions and corresponding statistical parameters for (a) $k_{1, t}$ and (b) $k_{2, t}$. 

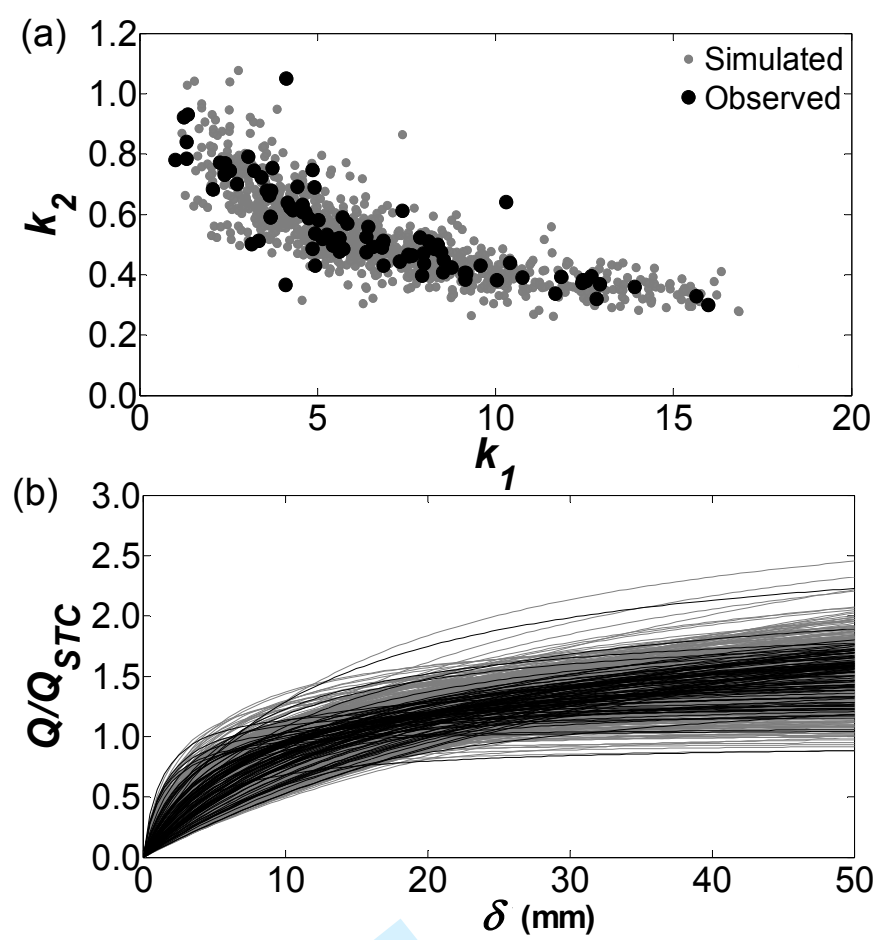

Fig. 3. Comparison of the observed and 1,000 simulated (a) model parameters, $k_{1}$ and $k_{2}$, and (b) corresponding load-displacement curves. 

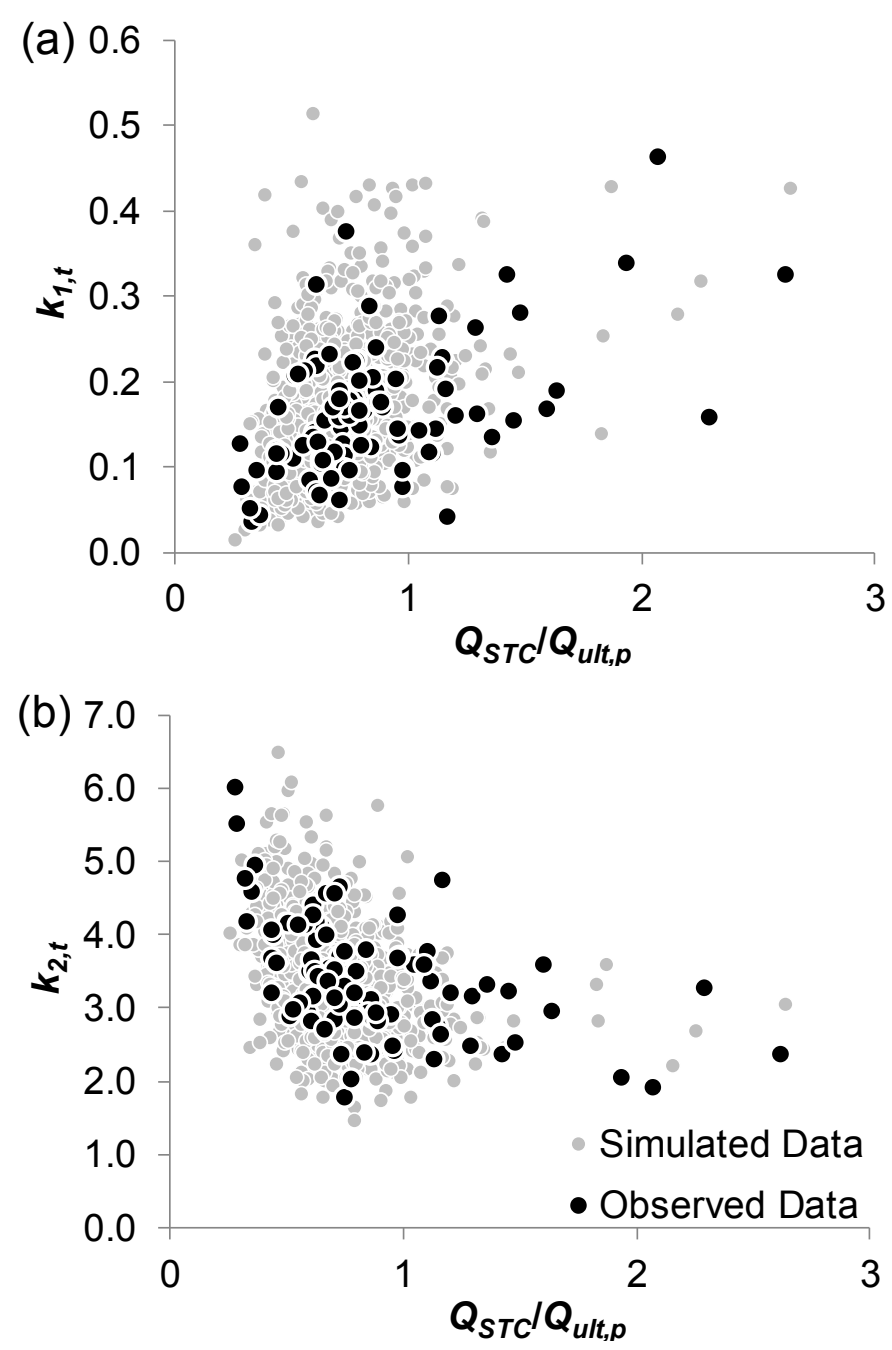

Fig. 4. The goodness-of-fit between the observed and simulated data for (a) $k_{1, t}$ and $Q_{S T C} / Q_{u l t, p}$, using a Gumbel copula rotated $180^{\circ}$ and (b) $k_{2, t}$ and $Q_{S T C} / Q_{u l t, p}$ using a Clayton copula rotated $180^{\circ}$. 

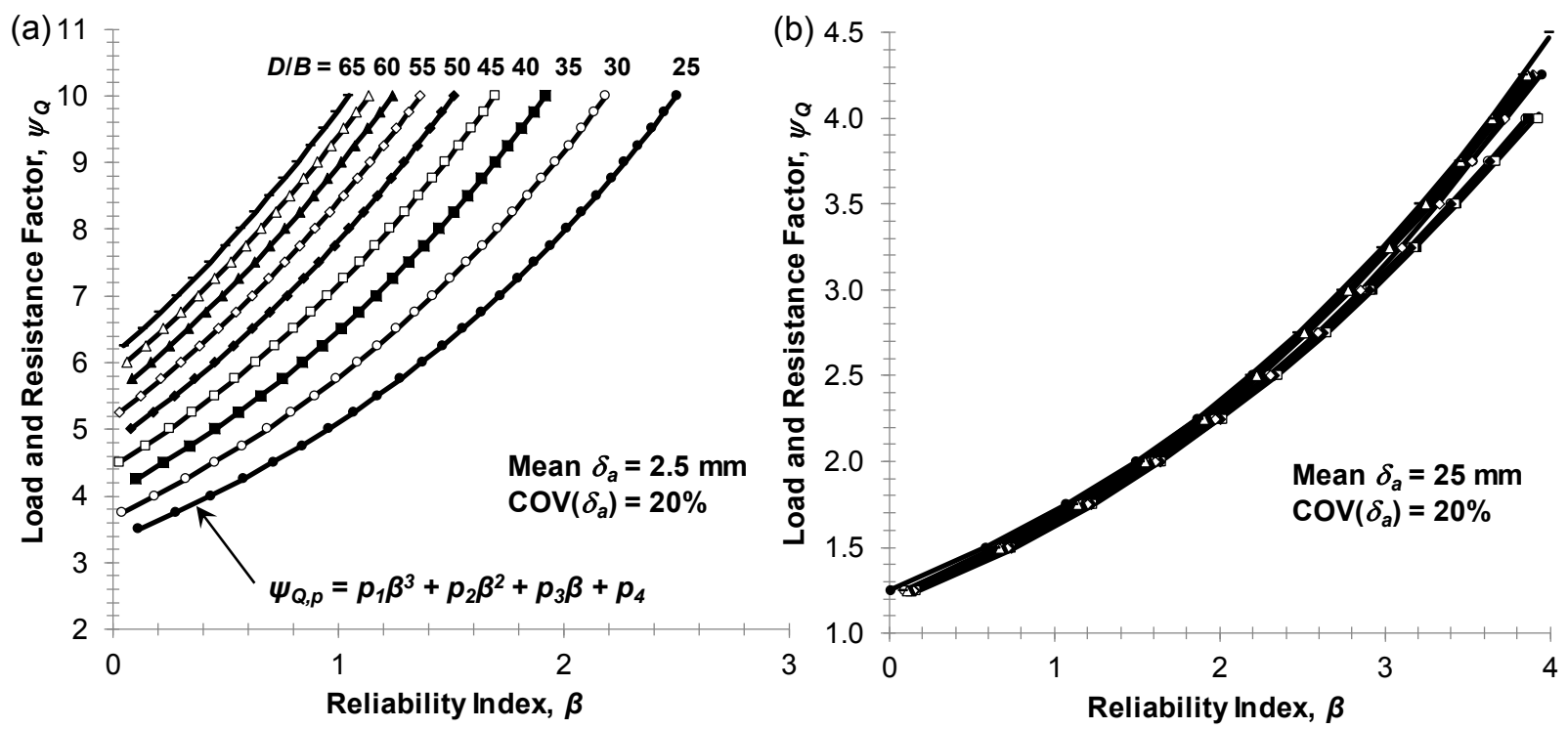

Fig. 5. The relationship between load-resistance factor and reliability index for $\operatorname{COV}\left(Q^{\prime}{ }_{\text {app }}\right)=10$ percent and $\operatorname{COV}\left(\delta_{a}\right)=20$ percent for (a) a mean allowable displacement of $2.5 \mathrm{~mm}$ and (b) 25 $\mathrm{mm}$ and for slenderness ratios of 25 to 65 .

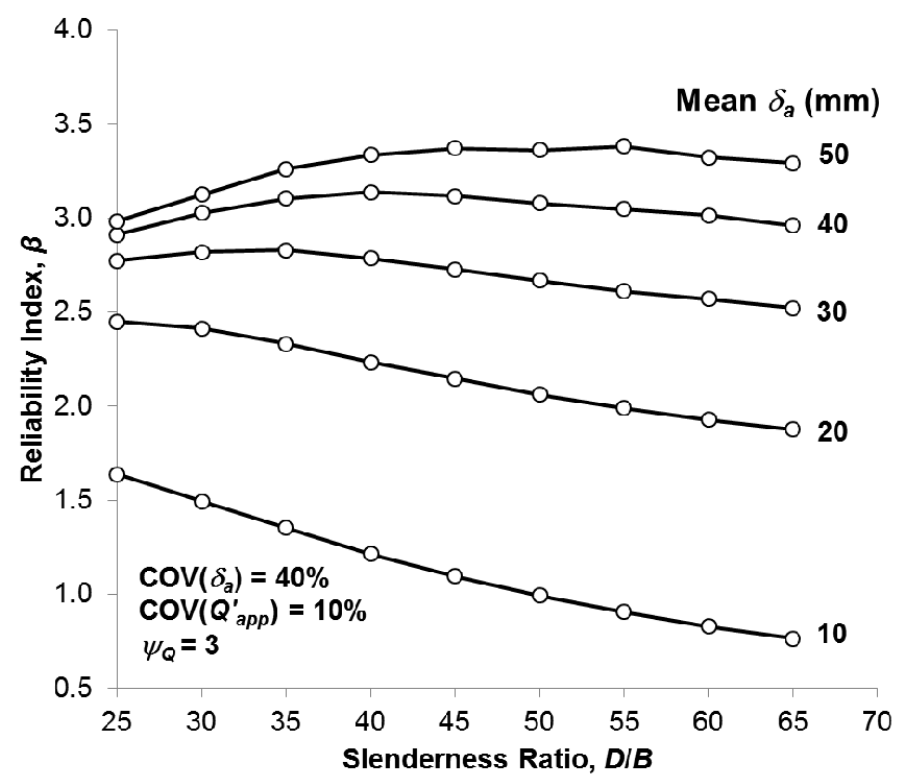

Fig. 6. The effect of slenderness ratio of reliability at the serviceability limit state for different mean allowable displacements and constant values of $\operatorname{COV}\left(\delta_{a}\right), \operatorname{COV}\left(Q^{\prime}{ }^{\prime}{ }^{\prime}\right)$, and $\psi_{Q}$. 
(a)

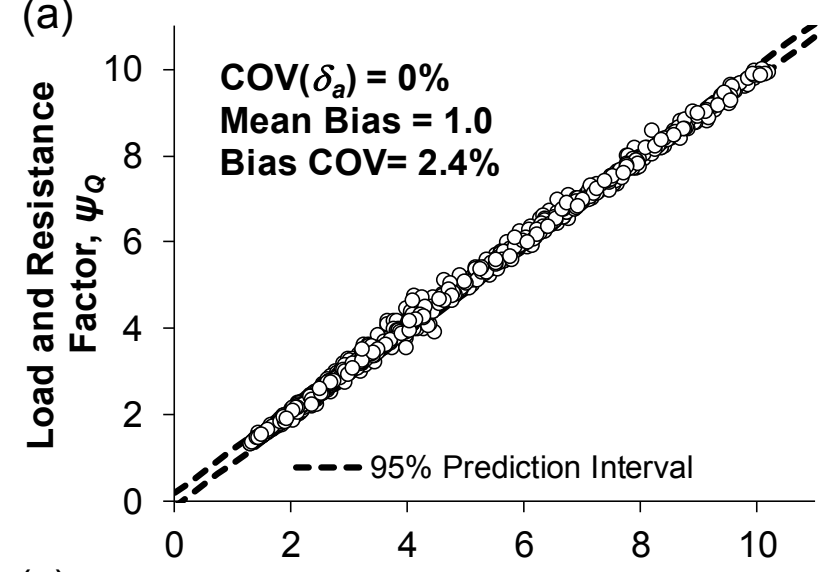

(c)

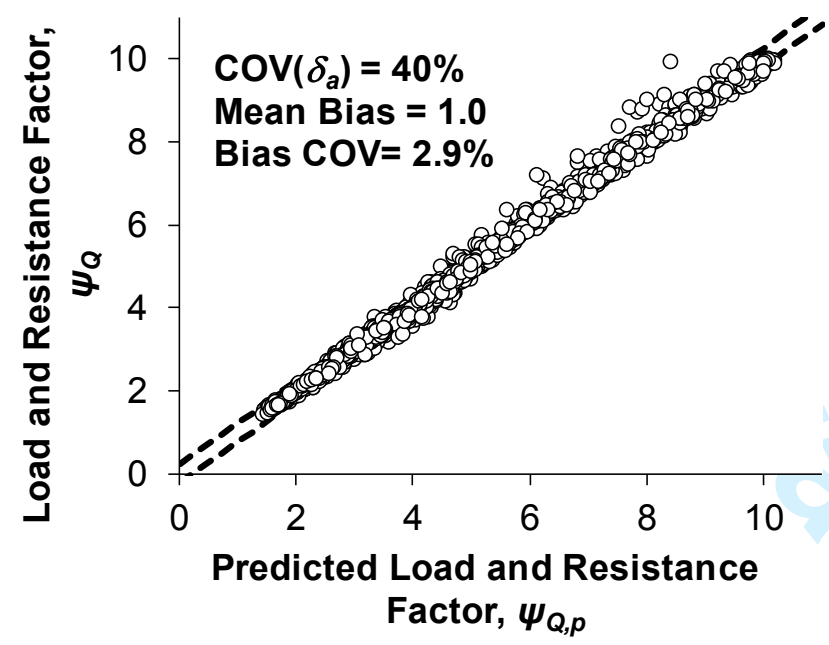

(b)

$10-\operatorname{cov}\left(\delta_{\mathrm{a}}\right)=20 \%$

8 - Bias $\operatorname{COV}=3.4 \%$

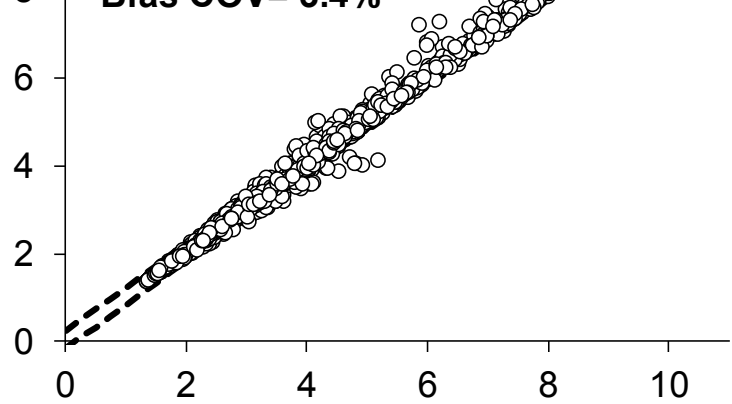

(d)

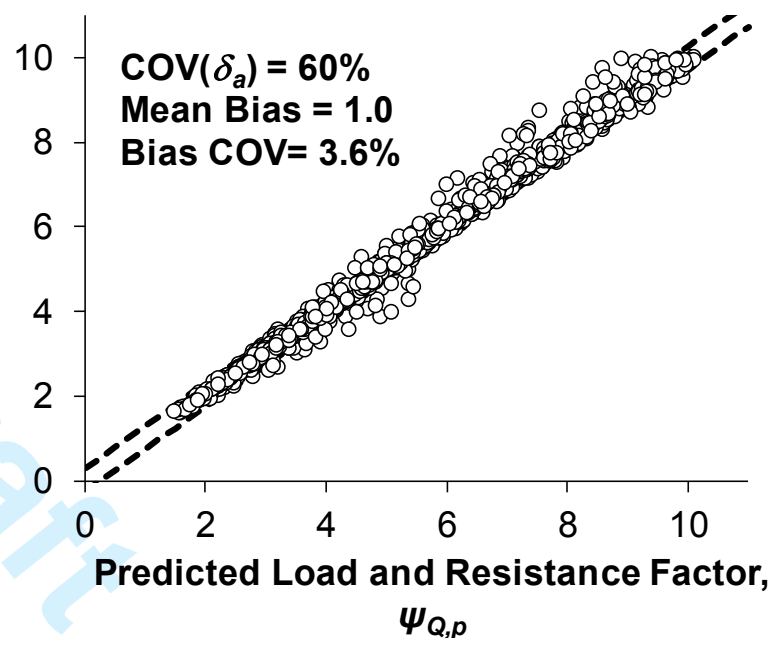

Fig. 7. Comparison of simulated and predicted load-resistance factors using the proposed serviceability limit state model for $\operatorname{COV}\left(Q^{\prime}{ }_{a p p}\right)$ equal to 10 percent and $\operatorname{COV}\left(\delta_{a}\right)=0,20,40$, and 60 percent. 


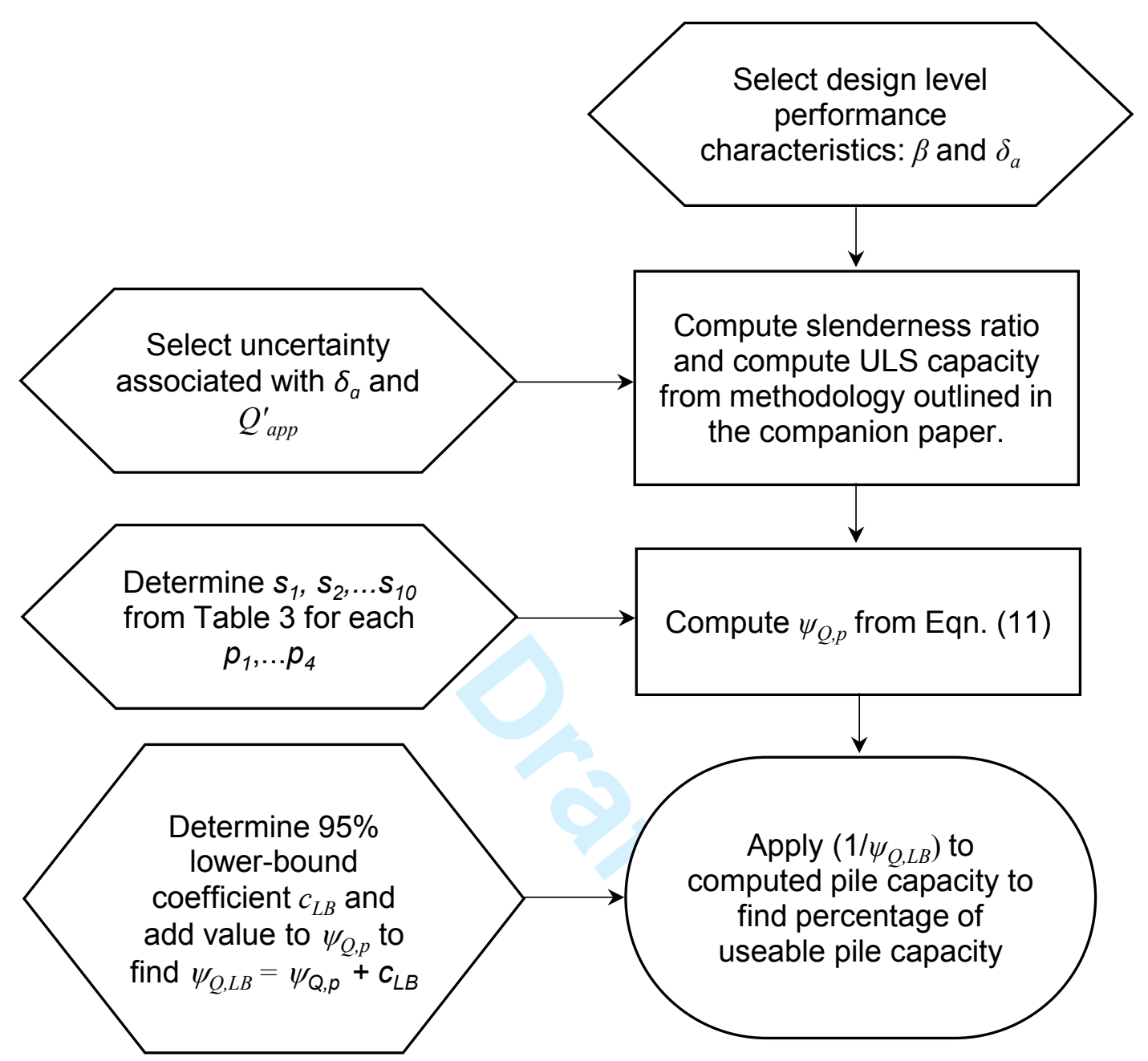

Fig. 8. Procedure for implementation of the proposed reliability-based serviceability limit state methodology to determine the appropriate load-resistance factor for ACIP piles in predominately granular soils. 
Table 1. Copula functions selected for evaluation, and their parameters and goodness-of-fit to the database.

\begin{tabular}{ccc}
\hline Copula Type & Copula Parameter, $\theta$ & $\begin{array}{c}\text { Bayesian Information } \\
\text { Criterion }\end{array}$ \\
\hline Gaussian & -0.868 & 54.0 \\
Frank & -10.126 & -113.8 \\
Clayton & -4.045 & 91.9 \\
Gumbel & -3.022 & -20.7 \\
Joe & -4.851 & 83.7 \\
\hline
\end{tabular}

Table 2. Summary of load and displacement parameters used for the Monte Carlo Simulations.

\begin{tabular}{cccc}
\hline Parameter & Nominal Value & COV $(\%)$ & Distribution \\
\hline$m_{S T C}$ & 0.69 & 27.9 & Truncated \\
$Q^{\prime}{ }_{a p p}$ & 1.00 & 10,20 & Lognormal \\
$\delta_{a}$ & $2.5,5.0, \ldots, 50$ & $0,20, \ldots, 60$ & Lognormal \\
$D / B$ & $25,30, \ldots, 65$ & - & - \\
\hline
\end{tabular}


Table 3. Summary of best-fit coefficients for calculating $p_{1}$ through $p_{4}$ (Eqn. 12) for selected combinations of $\operatorname{COV}\left(Q^{\prime}{ }_{a p p}\right)$ and $\operatorname{COV}\left(\delta_{a}\right)$.

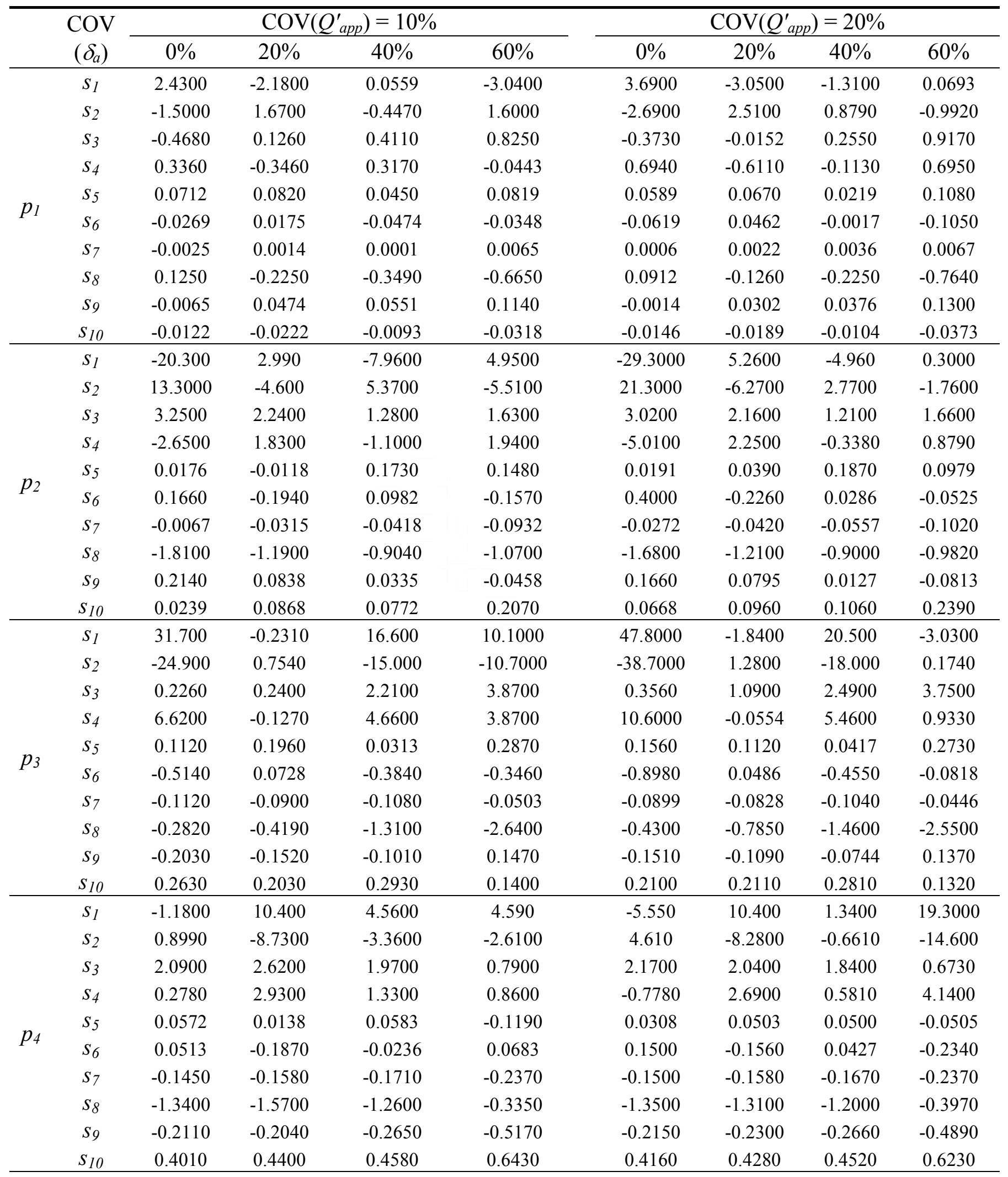


Table 4. The lower-bound coefficient, $c_{L B}$, for calculating the 95 percent lower-bound loadresistance factor, $\psi_{Q, L B}$, for selected combinations of $\operatorname{COV}\left(Q^{\prime}\right.$ app $)$ and $\operatorname{COV}\left(\delta_{a}\right)$.

\begin{tabular}{|c|c|c|c|c|c|c|c|c|}
\hline \multirow[b]{2}{*}{$\operatorname{COV}\left(\delta_{a}\right)$} & \multicolumn{4}{|c|}{$\operatorname{COV}\left(Q_{a p p}^{\prime}\right)=10 \%$} & \multicolumn{4}{|c|}{$\operatorname{COV}\left(Q_{a p p}^{\prime}\right)=20 \%$} \\
\hline & $0 \%$ & $20 \%$ & $40 \%$ & $60 \%$ & $0 \%$ & $20 \%$ & $40 \%$ & $60 \%$ \\
\hline$c_{L B}$ & 0.16 & 0.20 & 0.23 & 0.28 & 0.16 & 0.17 & 0.24 & 0.29 \\
\hline
\end{tabular}

